\title{
ROLE OF FOCUSED ABDOMINAL SONOGRAPHY FOR TRAUMA IN SOLID ORGAN INJURY IN PAEDIATRIC BLUNT ABDOMINAL TRAUMA
}

\author{
Rejum Ronya1, Rajib Ray Baruah², Nirmal Bhattacharyya3, Jayanta Kumar Goswami, Manoj Saha5, Rupnayan Goswami6, \\ Lalrin Siama
}

\author{
${ }^{1}$ Assistant Professor, Department of Paediatric Surgery, TRIHMS, Naharlagun, Arunachal Pradesh. \\ ${ }_{2}^{2}$ Assistant Professor, Department of Paediatric Surgery, GMCH, Guwahati, Assam. \\ ${ }^{3}$ Retired Professor, Department of Paediatric Surgery, GMCH, Guwahati, Assam. \\ ${ }^{4}$ Professor and HOD, Department of Paediatric Surgery, GMCH, Guwahati, Assam. \\ ${ }^{5}$ Associate, Department of Paediatric Surgery, GMCH, Guwahati, Assam. \\ ${ }^{6}$ Registrar, Department of Paediatric Surgery, GMCH, Guwahati, Assam. \\ ${ }^{7}$ Senior Resident, Department of Paediatric Surgery, GMCH, Guwahati, Assam.
}

\begin{tabular}{l}
\hline ABSTRACT \\
\hline BACKGROUND \\
The term Focused Assessment with Sonography for Trauma (FAST) was coined by Rozycki et al in 1996. It is now termed "focused \\
abdominal sonography for trauma". It is an emergency ultrasound scan done in abdominal trauma with focus on four quadrants of \\
abdomen- right upper quadrant, left upper quadrant, subxiphoid region and pelvis. It is a good rapid [only 2 to 3 minutes] \\
screening tool to guide surgeon regarding management of blunt abdominal trauma cases.
\end{tabular}

\section{MATERIALS AND METHODS}

This is descriptive study 66 patients [age range 3-12 years, with blunt trauma abdomen were subjected to a thorough clinical history, clinical examination and FAST Examination and in many cases compared with CT scan and operative findings.

\section{RESULTS}

Of 66 paediatric blunt abdominal trauma patients, 48 were male and 18 were female. FAST was done in 65 cases. In 49 cases, free fluid was detected whereas; in 16 cases no free fluid was detected. 46 cases were true positive, 15 were true negative. 3 false positive and 1 false negative. The sensitivity, specificity and accuracy of FAST were $93.7 \%, 94 \%$ and $90.6 \%$ respectively. There were 46 cases of abdominal visceral injury, of which 14 were bowel injuries, 32 solid abdominal organ injuries, mostly isolated and 11 had multiple organ injuries. FAST detected free fluid in all 32 cases of abdominal solid organ injuries. 57 cases were stable and only 9 were hemodynamically unstable.

\section{CONCLUSION}

FAST Examination in combination with clinical evaluation is a good initial screening tool in the management of blunt abdominal trauma in children, including abdominal solid organ injury.

\section{KEYWORDS}

Focused Abdominal Sonography for Trauma, Blunt Trauma Abdomen, Free Fluid, Road Traffic Accidents.

HOW TO CITE THIS ARTICLE: Ronya R, Baruah R, Bhattacharyya N, et al. Role of focused abdominal sonography for trauma in solid organ injury in paediatric blunt abdominal trauma. J. Evolution Med. Dent. Sci. 2018;7(17):2074-2077, DOI: $10.14260 /$ jemds/2018/465

\section{BACKGROUND}

Abdomen is the most commonly injured anatomic region after head and extremities injuries. The anatomic and physiologic differences in adults and children has its implications for paediatric trauma management.[1] As pathognomonic physical examination findings may not be present in many children with abdominal injury, FAST is used now a days for the rapid screening of intra-abdominal injury. The term Focused Assessment with Sonography for Trauma (FAST) was coined by Rozycki et al in 1996. It is now termed "focused abdominal sonography for trauma".

'Financial or Other Competing Interest': None.

Submission 28-02-2018, Peer Review 05-04-2018,

Acceptance 12-04-2018, Published 23-04-2018.

Corresponding Author:

Dr. Rejum Ronya,

Tomo Riba Institute of Health and Medical Sciences,

Naharlagun, C2-Sector, Itanagar, IMC-154,

Papum Pare District-791111, Arunachal Pradesh.

E-mail: ronyarejum@gmail.com

DOI: $10.14260 /$ jemds $/ 2018 / 465$

\section{(c) $(1)$}

It is an emergency ultrasound scan done in abdominal trauma with focus on four quadrants of abdomen- right upper quadrant, left upper quadrant, subxiphoid region and pelvis. It is a good rapid [Only 2 to 3 minutes] screening tool to guide surgeon regarding management of blunt abdominal trauma cases. It can be performed by surgeon himself at bedside. FAST can be performed simultaneously with resuscitation efforts during the initial trauma management and can be completed rapidly and is, therefore, also useful in hemodynamically unstable patients.[2] But, FAST does not accurately detect the extent (Grade) or the exact site of the organ injury. It is operator-dependent.

\section{MATERIALS AND METHODS}

This study is a descriptive study, carried out in Gauhati Medical College and Hospital in the department of paediatric surgery from January 2012 to December 2013. Sample size was taken for convenience. A total of 66 patients below age of 12 years, presented with blunt trauma abdomen. There were 48 male and 18 female patients. FAST examination of these patients was carried out in the department of pediatric 
surgery. Approval for the study was obtained from the Hospital Ethics committee. The following data were collected - name, age, time of injury and presentation, cause of injury, presence or absence of free fluid, site of organ injured, CT scan findings, conservative or operative treatment, remark and follow up. All patients in the study were subjected to a thorough clinical history, clinical examination and FAST Examination and in many cases compared with CT scan and operative findings. Treatment protocol followed as per findings of clinical evaluation, Fast, USG / CT scan.

Patients were examined with portable USG machine (EUB-405 plus ultrasound scanner HITACHI) available in the department of paediatric surgery, GMCH, Guwahati, either bedside or in the departmental USG/seminar room. 3.5 or 7.5 megahertz probe was used. Patients were examined in supine position mostly but for left upper quadrant examination, additional lateral position was used. All quadrants epigastric/subcardiac view, right upper quadrant view, left upper quadrant view and hypogastric view were examined.

\section{Inclusion Criteria}

All paediatric patients below 12 years, with blunt abdominal trauma admitted in the department of paediatric surgery ward, GMCH, from January 2012 to December 2013 were included in the study.

\section{Exclusion Criteria}

Paediatric penetrating abdominal trauma and abdominal gunshot injury cases were not included in the study.

The gold standard used in this study as a reference to sensitivity and specificity of FAST was CT scan of abdomen of paediatric population with blunt abdominal trauma.

\section{Statistical Analysis}

The data is collected and recorded in Microsoft Excel sheet. Chi-square test has been used to detect the statistical significance of the data. $P$ value is $<0.01$ which is statistically significant.

\section{RESULTS}

There were 66 paediatric blunt abdominal trauma patients [48 were male and 18 were female]. FAST was done in 65 cases. There were 49 FAST positive cases and 16 FAST negative cases [no free fluid was detected]. 46 cases were true positive, 15 were true negative. 3 false positive and 1 false negative. The sensitivity, specificity and accuracy of FAST were $93.7 \%, 94 \%$ and $90.6 \%$ respectively. There were 46 cases of abdominal visceral injury, of which 14 were bowel injuries, 32 solid abdominal organ injuries, mostly isolated and 11 had multiple organ injuries. Out of 32 children with solid organ injury, renal trauma, and spleen, were the most common isolated solid visceral injury, followed by liver, pancreas, suprarenal, and bladder. FAST detected free fluid in all 32 cases of abdominal solid organ injuries. In multiple solid organ injuries, Spleen was involved in 7 cases, Kidney in 6 , liver in 4, pancreas in 3, adrenal in 2 and bladder in 1 case with multiple organ injury.

Among the various causes of paediatric Blunt Abdominal Trauma, Road Traffic Accidents accounted for 33 cases, followed by fall from height in 14 cases, Bicycle injury in 6 cases and Animal hit in 3 cases. 57 cases were stable and only 9 were hemodynamically unstable. Conservative management was done in 45 cases whereas operation in 21 cases. Conservative management in 31 out of 32 cases of confirmed solid organ injury was successful. In total, interventions were needed in 21 cases and 18 of them were FAST positive cases.

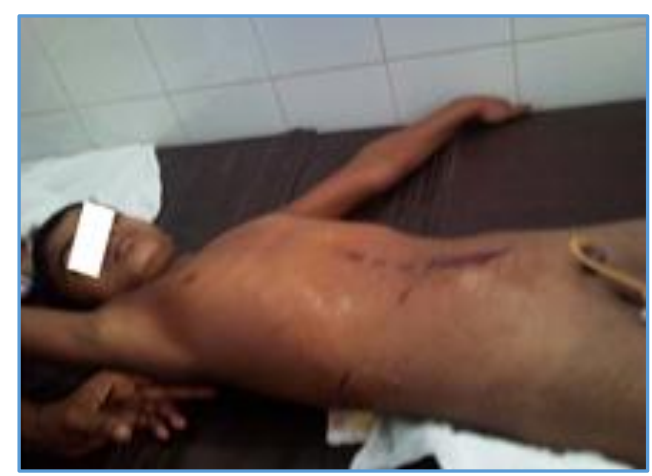

Figure 1. BTA with Psoas Collection

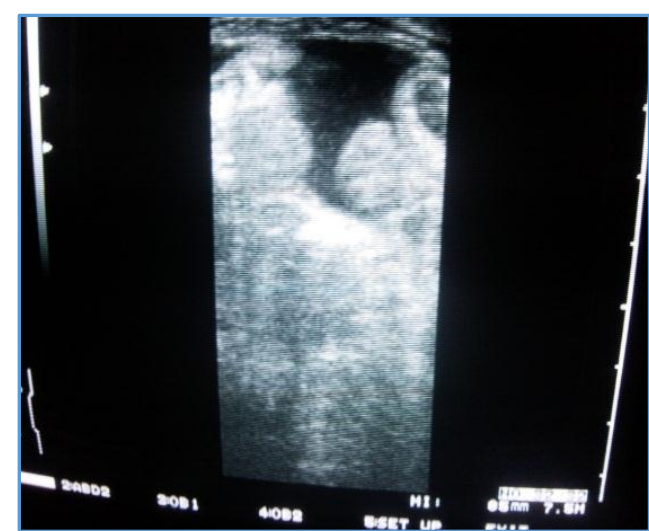

Figure 2. Free Fluid on FAST in BTA

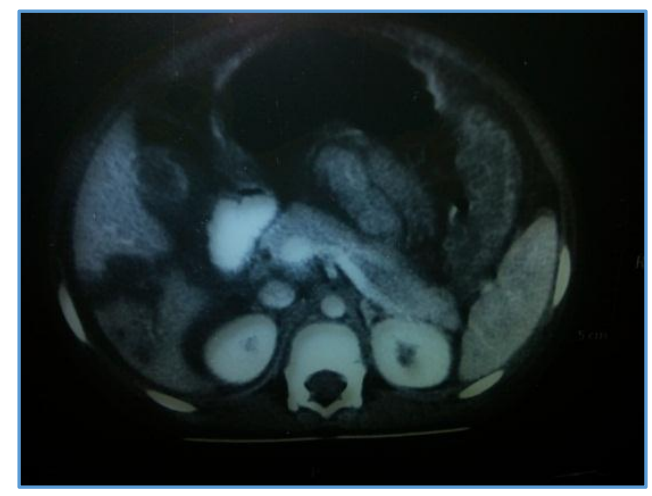

Figure 3. CT Scan showing Hepatic Laceration

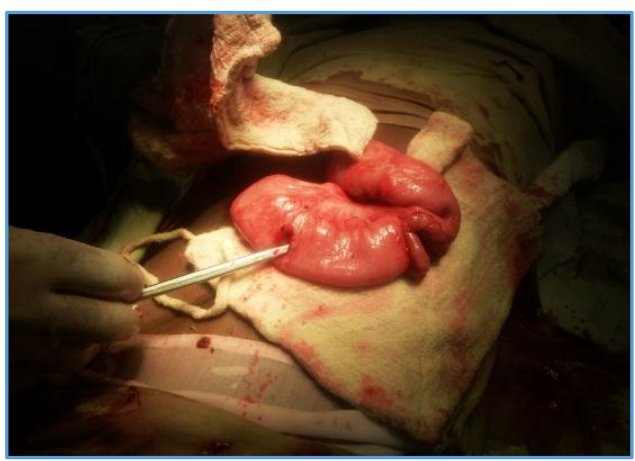

Figure 4. BAT Traumatic Jejunal Perforation 


\section{DISCUSSION}

There were 48 males and 18 females. In other series also, male predominance was noted, which are comparable with our series. Most of the patients were in haemodynamically stable. Out of 66 patients, 55 were haemodynamically stable and only 9 were unstable. Natarajan B., Lee Brett. C, Nira. B. Razi, Patel N. Y and Holmes J in their studies reported more or less similar finding. There are varied reports of the utility of FAST in paediatric blunt trauma abdomen in terms of sensitivity and specificity.[3-7] In this series sensitivity and specificity were found to be $93.7 \%$ and $94 \%$ respectively. Coley Brian D. et al and Patel Jateen C reported sensitivity and specificity of $95 \%, 95 \%$ and $33 \%, 95 \%$ respectively. ${ }^{[8-9]}$ There were 12 patients in the age group less than 5 years, 40 patients in the age group between $5-9$ years and 12 patients above 10 years in the present series. Most common age group was between 5 years to 10 years. This pattern was seen in other series also (Soundappan et al and Ahmad F et al).[10-11] There are varied results of FAST examination in different series. Studies by Nira Razi, Coley and Ahmad F et al showed few FAST positive cases relative to FAST negative results. ${ }^{[12]}$ In a study by Beat Schnuriger et al in which they reported 181 FAST positive cases compared to 45 FAST negative cases.[13] This is comparable with our series of 49 FAST positive cases against only 16 FAST negative cases. There are varied reports of FAST in terms of true positive, true negative, false positive and false negative. In our series, there were 46 true positive cases, 3 false positive cases, 15 true negative cases and only one false negative case. Our series was the smallest one, while series by Natarajan of 2105 patients being the largest one.

Study by various authors have shown different results of FAST and CT scan. Soundappan et al reported that all the patients with positive FAST examination were found to be positive on CT scan too, which is similar to finding in our series. Coley Brian reported only $11.2 \%$ CT scan positive cases in their FAST-positive cases and 31\% CT scan positivity in their FAST-negative patients, $1.8 \%$ CT scan negative but FAST positive cases and $68.2 \%$ had both FAST and CT scan negative cases. There was no CT scan negative result in FAST positive cases as reported by MC Gahan, Soundappan, Benya Ellen and present series.[14-15] In the present series, there was no FAST negative and CT scan negative case. There were 32 cases of solid organ injuries in this series, and in all cases hemoperitoneum was present, whereas all other series reported significant percentage of cases with solid organ injuries without hemoperitoneum ranging from $20 \%$ by Beat Schnuriger et al to $40 \%$ by Patel N Y et al. While Brown et al and Soudack M reported 26\% and 26.5\% respectively.[16-17] Road traffic accidents were the commonest cause of Blunt Abdominal Trauma in all series, followed by fall from height in most series. In the western series, fall from building was common, whereas in our series fall from trees was more common. In the present series, there were 34 cases of Road traffic accidents, 18 cases of fall, 6 cases of bicycle related injury, 3 cases of animal hits and sports injury each and 2 others out of 66 total cases under study. In the western series, blunt abdominal trauma following horse kick were common cause of animal hits whereas, blunt abdominal trauma due to hit by cow was commoner in our series. Other categories include assault and child abuse etc.
There are varied reports of incidence of intra-abdominal organ injuries by different authors. Benya et al observed that liver was the most commonly involved organ in paediatric Blunt Abdominal Trauma, whereas spleen was reported to be the most commonly injured organ by most authors including Wessel, Filiatrault, Schnuriger, Michiro Sato et al.[17-19] In the present series, bowel injury [14 out of 46 total intraabdominal organ injuries] was the most common organ injured and spleen along with kidney were the most common solid organ injured [12 each]. Most of the series reported low rate of operative intervention in solid organ injury. Michiro Sato et al reported the highest rate of operative intervention [26\%] in their study of 604 patients of which 122 had intraabdominal organ injuries, while our series had the lowest rate of operative intervention [3\%] for 32 solid intraabdominal organ injuries from 66 patients.

\section{CONCLUSION}

Incidence of blunt trauma abdomen is more in male children than female (male 72\%). Road traffic accident was the commonest cause of paediatric Blunt Abdominal Trauma. Spleen and kidney were the most common solid organs injured in paediatric blunt abdominal trauma. USG is reliable for the detection of free fluid as emergency screening tool and the identification of solid-organ injuries in combination with clinical evaluation and CT Scan is the gold standard for detection of solid abdominal organ injury despite its poor sensitivity for intestinal injuries. FAST definitely avoids unnecessary CT Scan.

In hemodynamically stable patients with a reliable physical examination, clinical findings may be used to select patients who may be safely observed.

Most of the patients of intraabdominal solid organ injuries due to paediatric blunt trauma abdomen can be managed conservatively whereas bowel injuries need laparotomy.

This study shows that FAST Examination in combination with clinical evaluation is a good initial screening tool in the management of blunt abdominal trauma in children.

However, this is a small prospective study because of time constraint and further studies with larger population, are required to confirm the role of FAST in the management of paediatric blunt abdominal trauma.

\section{REFERENCES}

[1] Avarello JT, Cantor RM. Pediatric major trauma: an approach to evaluation and management. Emerg Med Clin N Am 2007;25(3):803-36.

[2] Matsushima K, Frankel HL. Beyond focused assessment with sonography for trauma: ultrasound creep in the trauma resuscitation area and beyond. Current Opinion in Critical Care 2011;17(6):606-12.

[3] Natarajan B, Gupta PK, Cemaj S, et al. FAST scan: Is it worth doing in hemodynamically stable blunt trauma patients? Surgery 2010;148(4):695-701.

[4] Lee BC, Ormsby EL, McGahan JP, et al. The utility of sonography for the triage of blunt abdominal trauma patients to exploratory laparotomy. AJR Am J Roentgenol 2007;188(2):415-21. 
[5] Beck-Razi N, Fischer D, Michaelson M, et al. Utility of focused assessment with sonography for trauma as a triage tool in multiple-casualty incidents during the second Lebanon war. J Ultrasound Med 2007;26(9):1149-56.

[6] Patel NY, Riherd JM. Focused assessment with sonography for trauma: methods, accuracy and indications. Surg Clin North Am 2011;91(1):195-207.

[7] Holmes JF, Gladman A, Chang CH. Performance of abdominal ultrasonography in pediatric blunt trauma patients: a meta-analysis. J Pediatr Surg 2007;42(9):1588-94.

[8] Coley BD, Mutabagani KH, Martin LC, et al. Focussed Abdominal Sonography for Trauma (FAST) in children with blunt abdominal trauma. The Journal of Trauma: Injury, Infection and Critical Care 2000;48(5):902-6.

[9] Patel JC, Tepas JJ. The efficacy of Focused Abdominal Sonography for Trauma (FAST) as a screening tool in the assessment of injured children. Journal of Pediatric Surgery 1999;34(1):44-7.

[10] Soundappan SV, Holland AJ, Cass DT, et al. Diagnostic accuracy of surgeon-performed focused abdominal sonography Trauma (FAST) in blunt paediatric trauma. Injury 2005;36(8):970-5.

[11] Faruque AV, Qazi SH, Khan MA, et al. Focused Abdominal Sonography for Trauma (FAST) in blunt paediatric abdominal trauma. JPMA 2013;63(3):361-4.

[12] Schnüriger B, Kilz J, Inderbitzin, et al. The accuracy of FAST in relation to grade of solid organ injuries: a retrospective analysis of 226 trauma patients with liver or splenic lesion. BMC Med Imaging 2009;9:3.
[13] McGahan JP, Horton S, Gerscovich EO, et al. Appearance of solid organ injury with contrastenhanced sonography in blunt abdominal trauma: preliminary experience. American Journal of Roentgenology 2006;187(3):658-66.

[14] Benya EC, Lim-Dumhan Je, Landrum 0, et al. Abdominal sonography in examination of children with blunt abdominal trauma. American Journal of Roentgenology 2000;174(6):1613-6.

[15] Brown MA, Casola G, Sirlin CB, et al. Importance of evaluating organ parenchyma during screening abdominal ultrasonography after blunt trauma. J Ultrasound Med 2001;20(6):577-83.

[16] Soudack M, Epelman M, Maor R, et al. Experience with Focused Abdominal Sonography for Trauma (FAST) in 313 pediatric patients. J Clin Ultrasound 2004;32(2):53-61.

[17] Wessel LM, Scholz S, Jester I, et al. Management of kidney injuries in children with blunt abdominal trauma. J Pediatr Surg 2000;35(9):1326-30.

[18] Filiatrault D, Garel L. Commentary: pediatric blunt abdominal trauma-to sound or not to sound? Pediatric Radiol 1995;25(5):329-31.

[19] Sato M, Yoshii H. Re-evaluation of ultrasonography for solid-organ injury in blunt abdominal trauma. JUM 2004;23(12):1583-96. 